\title{
Review Article \\ Potential Mechanisms for Racial and Ethnic Differences in Antimüllerian Hormone and Ovarian Reserve
}

\author{
Reshef Tal and David B. Seifer \\ Genesis Fertility \& Reproductive Medicine, Division of Reproductive Endocrinology and Infertility, Maimonides Medical Center, \\ 1355 84th Street, Brooklyn, NY 11228, USA \\ Correspondence should be addressed to Reshef Tal; resheft@gmail.com
}

Received 11 June 2013; Revised 21 October 2013; Accepted 21 October 2013

Academic Editor: Petra Stute

Copyright (C) 2013 R. Tal and D. B. Seifer. This is an open access article distributed under the Creative Commons Attribution License, which permits unrestricted use, distribution, and reproduction in any medium, provided the original work is properly cited.

\begin{abstract}
Accumulating evidence suggests that reproductive potential and function may be different across racial and ethnic groups. Racial differences have been demonstrated in pubertal timing, infertility, outcomes after assisted reproductive technology (ART) treatment, and reproductive aging. Recently, racial differences have also been described in serum antimüllerian hormone (AMH), a sensitive biomarker of ovarian reserve, supporting the notion that ovarian reserve differs between racial/ethnic groups. The existence of such racial/ethnic differences in ovarian reserve, as reflected by $\mathrm{AMH}$, may have important clinical implications for reproductive endocrinologists. However, the mechanisms which may underlie such racial differences in ovarian reserve are unclear. Various genetic factors and environmental factors such as obesity, smoking, and vitamin D deficiency which have been shown to correlate with serum AMH levels and also display significant racial/ethnic variations are discussed in this review. Improving our understanding of racial differences in ovarian reserve and their underlying causes may be essential for infertility treatment in minority women and lead to better reproductive planning, improved treatment outcomes, and timely interventions which may prolong reproductive lifespan in these women.
\end{abstract}

\section{Introduction}

Accumulating evidence suggests that reproductive potential and function may be different across racial and ethnic groups. Differences have been demonstrated in pubertal timing, infertility, outcomes after assisted reproductive technology (ART) treatment, and reproductive aging. Black females are known to initiate puberty one year earlier and to achieve pubertal milestones earlier than white females $[1,2]$. While infertility affects women of all races and ethnicities, US black and Hispanic women have disproportionately greater rates of infertility than whites [3], with recent evidence suggesting that these differences have been widening [4]. Moreover, a mounting body of evidence shows racial differences in ART treatment outcomes, with black, Hispanic, and Asian races associated with significantly lower pregnancy rates and live birthrates than whites [5-9]. While environmental, socioeconomic status, behavioral, and anatomic factors are likely contributors to racial disparities in ART outcomes, significant differences still remain even when these factors are controlled for $[10,11]$, suggesting that genetic factors may also play a role. Racial/ethnic differences have also been described in reproductive aging, as reflected by menopausal timing [12-14] and hormonal fluctuations [15-17]. Furthermore, race may also affect the prevalence of premature menopause, as differences have been noted between white, black, and Hispanic women [18]. Thus, the longevity of ovarian function may be influenced by race/ethnicity.

These racial/ethnic differences in reproductive potential and function suggest a racial difference in ovarian reserve. Antimüllerian hormone (AMH) is widely considered a highly sensitive marker of ovarian reserve. It is a member of the transforming growth factor- $\beta$ superfamily. AMH suppresses the cyclical recruitment of primordial follicles at the pool of growing follicles and is primarily produced by the pool of small and large preantral and early antral follicles, which are believed to serve as a proxy for the number of primordial follicles in the ovary $[19,20]$. It has been suggested that AMH may be the most accurate biomarker of ovarian aging and offer several advantages over traditional biomarkers of 
ovarian reserve [19]. Compared with other hormonal markers of reproductive aging, AMH begins to gradually decline earlier in life $[19,21,22]$, and its levels are not influenced by menstrual cycle timing, hormonal contraceptives, or pregnancy [19, 23-25].

Seifer et al. reported a significant difference in the mean level of AMH as a function of race or ethnicity [26]. They analyzed changes in $\mathrm{AMH}$ in a racially diverse, multicenter cohort study of HIV-infected women and high-risk seronegative women enrolled in the Women's Interagency HIV Study (WIHS). AMH levels were assessed at two time points in the study (median age: 37.5 years and 43.3 years). After controlling for age, BMI, smoking, and HIV status, black women demonstrated average AMH values that were $25.2 \%$ lower over time than those in whites $(P=0.037)[26]$. In addition, AMH levels in Hispanic women were $24.6 \%$ lower over time than those in white women in the adjusted analysis, but this difference did not reach statistical significance $(P=$ 0.063).This study provided the first biochemical evidence of racial differences in ovarian reserve, as measured by $\mathrm{AMH}$. These findings have been recently corroborated by Gleicher et al. who reported that black women show a significantly greater age-related decline in $\mathrm{AMH}$ over time compared with white women [27]. Since the existence of racial/ethnic differences in ovarian reserve (as reflected by $\mathrm{AMH}$ ) is expected to have important clinical implications for reproductive planning and infertility treatment of minority women, this review aims to shed light on and discuss possible underlying mechanisms for such racial and ethnic differences in $\mathrm{AMH}$. While $\mathrm{AMH}$ is a sensitive marker of ovarian reserve, it is important to consider general limitations of currently available $\mathrm{AMH}$ assays when interpreting studies on $\mathrm{AMH}$. Both the DSL and GenII AMH assays have been shown to exhibit significant within-subjects sample variability, likely related to instability of AMH under certain storage and assay conditions $[28,29]$. A more robust $\mathrm{AMH}$ assay is expected to become available soon and should resolve these issues of $\mathrm{AMH}$ sample reproducibility in the future.

\section{Genetic Factors}

During fetal life, the primordial follicle pool is formed and increases initially to a peak of 6 to 7 million oocytes at 20 wk gestation [30]. Hereafter, the primordial follicle pool declines dramatically until there are approximately 1 million oocytes within the ovaries at birth [31]. Constant recruitment of primordial follicles into the growing follicle pool takes place throughout a woman's life, which is referred to as initial recruitment. By the time of puberty approximately 500,000 follicles remain, declining to $10,000-50,000$ by the late 30 s; during reproductive years, ongoing growth of follicles into antral stage and loss of follicles due to atresia lead to a gradual decrease in the number of oocytes, with eventual exhaustion of the follicle pool and menopause as the final result [30-32]. There is great variability in the quantity and quality of the oocyte pool, or ovarian reserve, among women. There is also wide variability in reproductive potential and the timing of reproductive events such as menarche and menopause, both of which have strong genetic heritability, based on several twin and family studies [33-35]. Ovarian aging, which leads to menopause with the exhaustion of the follicular pool, also seems to have a genetic component [36]. Therefore, it is likely that genetic factors play an important role in racial/ethnic differences in these reproductive traits and, specifically, ovarian reserve. However, very few studies have examined possible genetic associations between race/ethnicity and $\mathrm{AMH}$.

In the first genome-wide association study (GWAS), to evaluate genetic associations with hormone markers of ovarian reserve, Schuh-Huerta et al. analyzed genetic variants associated with FSH and $\mathrm{AMH}$, as surrogate measures of ovarian reserve, in a multiethnic fertile population of women [37]. Their study population included 232 Caucasian and 200 African American women who aged 25-45 and were prospectively enrolled in a community-based cohort. The authors found nominal genetic variants which were associated with $\mathrm{FSH}$ and $\mathrm{AMH}$ levels in both ethnic groups. Two genetic variants marginally associated with $\mathrm{AMH}$ were found in Caucasian women, located upstream of the JARID2 (jumonji, AT rich interactive domain 2) gene at 6p23 [37]. JARID2 is an ortholog of the mouse jumonji gene, which encodes a DNAbinding nuclear protein and is regulator of histone methyltransferases that negatively regulates cell growth and proliferation and is expressed in both human and mouse ovaries [38]. Therefore, JARID2 could play a role in cell growth within the developing ovary. In a related study, the same group investigated genetic variants associated with ovarian reserve as measured by antral follicular count (AFC) [39]. Interestingly, of the top 16 genetic variants associated with AFC in their study, 7 were associated with AMH levels. This is not surprising, as the number of preantral and antral follicles is thought to determine serum AMH level. Importantly, none of the associated genes in these studies have known roles in ovarian function and now represent an interesting group of candidate genes for further investigation. Future studies should also determine if any of these genetic variants may be responsible for racial/ethnic differences in AMH levels.

Gleicher et al. reported that the distribution of fragile $\mathrm{X}$ mental retardation (FMR1) genotypes correlates with serum AMH level [40]. Based on a normal range of 26-34 (median 30) CGG repeats, the authors used CGG counts on the two $\mathrm{X}$ chromosome alleles to define whether a genotype is normal (norm), heterozygous (het), or homozygous (hom). An individual was defined as norm when both alleles were within range, het by one allele outside, and norm/low or norm/high, depending on the abnormal count allele being above or below normal range. Both alleles outside range are defined as hom. It was found that $\mathrm{AMH} \leq 0.8 \mathrm{ng} / \mathrm{mL}$ was significantly associated with the number of CGG repeats; every decrease by five CGG repeats in the het-norm/low group increased the likelihood of diminished ovarian reserve by $40 \%$, while every increase by five CGG repeats in the hetnorm/high group increased the risk by $50 \%$ [40]. Moreover, FMR1 genotype was found to be associated with specific ovarian aging patterns. Women with het-norm/low genotype showed high ovarian reserve when they were young, which rapidly declined with age. In contrast, the het-norm/high genotype was associated with low ovarian reserve at young age but relative preservation of ovarian reserve into older ages 
$[41,42]$. The same investigators reported that FMR1 genotypes vary between Caucasian, African, and Asian women [43], suggesting that FMR1 genotype may be linked to racial differences in AMH. In their study, African women showed a relatively high ovarian reserve at young age, characterized by the lowest FSH, the highest AMH, and the highest oocyte yield among races; yet, as they age they demonstrate the largest decline in $\mathrm{AMH}$ and oocyte yield and the poorest ovarian reserve compared to Caucasian and Asian women [27]. In contrast, Asian women showed a relatively low ovarian reserve in young age but the smallest decline in $\mathrm{AMH}$ and disproportional preservation of ovarian reserve at older ages compared to Caucasians and African women [27]. Remarkably, African women demonstrate a preponderance of the het-norm/low FMR1 genotype, while Asian women show a preponderance of the het-norm/high genotype [27]. Thus, FMR1 genotype may account for the observed racial differences in AMH and ovarian aging patterns.

BRCA1 and BRCA2 are crucial members of the DNA double-strand break repair family of genes, and mutations in the BRCA genes are associated with risk of breast, ovarian, and other cancers $[44,45]$. Women who carry mutations in the BRCA1 gene show low response to ovarian stimulation and experience earlier menopause $[46,47]$. Recently, it was reported that women who are BRCA mutation carriers display significantly lower serum AMH level than noncarriers $(1.22 \pm 0.92 \mathrm{ng} / \mathrm{mL}$ versus $2.23 \pm 1.56 \mathrm{ng} / \mathrm{mL} ; P<0.0001)$ [48] These observations support the possible role of DNA doublestrand break repair in maintenance of human ovarian reserve and indicate that ovarian reserve is prematurely diminished in women with BRCA1 mutations. Several studies reported on variation in the prevalence of BRCA mutation carriers in women with breast cancer among various racial/ethnic groups. In a large US study which included 1727 breast cancer female patients younger than age 65 at diagnosis, estimates of BRCA1 prevalence were the highest in Hispanic patients (3.5\%), followed by non-Hispanic whites $(2.2 \%)$, African Americans (1.3\%), and Asian Americans (0.5\%) [49]. Prevalence was found to be particularly high in young $(<35$ years) African American patients (16.7\%) [49]. Consistent with this study, similarly lower BRCA1 mutation prevalence rates in black patients compared with white patients were reported in 2 other population-based series of patients with breast cancer $[50,51]$. In contrast to data on BRCA1 mutation frequency in the female breast cancer population, these data in the general population are very limited. Therefore, large population-based studies would be needed to establish the BRCA1 mutation frequency in the general population of different racial/ethnic groups of women and determine whether the association of BRCA1 mutation with diminished ovarian reserve and $\mathrm{AMH}$ may play a role in racial/ethnic differences in AMH (see Table 1).

\section{Environmental Factors}

Various environmental and lifestyle factors have been associated with serum AMH levels and may be implicated in racial/ethnic differences in AMH levels between women. Obesity is at epidemic proportions in the United States with recent data from the National Health and Nutrition Examination Survey showing that the combined prevalence of overweight and obesity was $64 \%$ in 2007-2008 among American women [52]. There is significant variation in obesity rates among American women according to race with blacks displaying the highest prevalence (49.6\%), followed by Hispanics (43\%) and whites (33\%) [52]. Apart from being a known risk factor for diabetes, hypertension, cardiovascular disease, stroke, and certain cancers, overweight and obesity are also associated with poor ART outcomes in most studies [53-55], though the findings are not universal [56]. These observations suggest a possible association between obesity and lower ovarian reserve. Freeman et al. were the first to report an association between AMH levels and obesity [57]. In a cross-sectional study of AMH levels in late reproductiveage women, they found that $\mathrm{AMH}$ levels were $65 \%$ lower in obese women $\left(\mathrm{BMI} \geq 30 \mathrm{~kg} / \mathrm{m}^{2}\right)$ compared to nonobese women $\left(\mathrm{BMI} \leq 30 \mathrm{~kg} / \mathrm{m}^{2}\right)(0.016 \mathrm{ng} / \mathrm{mL}$ and $0.046 \mathrm{ng} / \mathrm{mL}$, resp.). In their longitudinal analysis of a subgroup, obese women had significantly lower mean AMH levels over the 8-year interval compared to the nonobese women, corroborating the cross-sectional study results [57]. Consistent with these findings, in a study that was conducted to examine the impact of oral contraceptives on serum AMH levels by obesity status in reproductive-age women, it was found that $\mathrm{AMH}$ levels were 34\% lower in the obese group compared to normal BMI women $(2.9 \pm 2.1$ versus $4.4 \pm 1.8 \mathrm{ng} / \mathrm{mL}$, resp.) [58]. More recently, Buyuk et al. found a similar negative association between $\mathrm{AMH}$ and BMI among infertile women with diminished ovarian reserve, with mean random serum AMH levels being 33\% lower in overweight and obese women compared with normal weight women [59]. However, in this study the investigators did not find an association between $\mathrm{AMH}$ and BMI in women with normal ovarian reserve [59].

The mechanisms by which obesity may influence ovarian function and AMH are unclear. One possible mechanism is lipotoxic effects on granulosa cells. It was recently demonstrated that mice fed a high-fat diet exhibit increased anovulation and decreased fertilization rates, concomitant with increased lipid accumulation, endoplasmic reticulum stress, mitochondrial dysfunction, and apoptosis in granulosa and cumulus cells [60]. In the same study, signs of lipotoxicity were observed in the follicular fluid of obese women undergoing controlled ovarian stimulation compared with normal weight women [60]. These findings support the notion that obesity has a detrimental effect on ovarian reserve, which is reflected by lower AMH. However, Su et al. reported that while AMH was lower in obese compared to normal weight late reproductive age women, no difference was found in antral follicle count, suggesting that the decrease in $\mathrm{AMH}$ level seen in obese women results from a physiologic process other than reduced ovarian reserve [61]. It is plausible that hormone metabolism, sequestration, or clearance may be altered in obese women. Consistent with this hypothesis, adiponectin, which is secreted from white adipose tissue and its serum levels are decreased in obese women [62], has been shown to modulate ovarian steroidogenesis in conjunction with insulin and gonadotropins [63]. Moreover, in a recent 
TABLE 1: Potential factors and associated mechanisms underlying racial/ethnic differences in serum antimüllerian hormone (AMH) levels.

\begin{tabular}{|c|c|c|}
\hline Factors & Nature of association with AMH & Potential mechanism/s \\
\hline \multicolumn{3}{|l|}{ Genetic factors } \\
\hline JARID2 gene & $\begin{array}{l}\text { Marginal association with serum AMH level in } \\
\text { genome-wide association studies }[37,39]\end{array}$ & $\begin{array}{l}\text { JARID2 negatively regulates cell growth and proliferation } \\
\text { and is expressed in both human and mouse ovaries [38] }\end{array}$ \\
\hline FMR1 genotype & $\begin{array}{l}\text { AMH } \leq 0.8 \mathrm{ng} / \mathrm{mL} \text { was significantly associated } \\
\text { with the number of CGG repeats [40] }\end{array}$ & Theoretical altered FMR1 gene expression \\
\hline BRCA1 mutation & $\begin{array}{l}\text { BRCA1 mutation carriers display significantly } \\
\text { lower serum AMH levels [48] }\end{array}$ & $\begin{array}{l}\text { Loss of BRCA1 increases DNA double-strand breaks in } \\
\text { human and mouse oocytes and is associated with } \\
\text { reduced oocyte survival in mice [48] }\end{array}$ \\
\hline \multicolumn{3}{|l|}{ Environmental factors } \\
\hline Obesity & $\begin{array}{l}\text { Inverse correlation between BMI and serum } \\
\mathrm{AMH}[57-59,61]\end{array}$ & $\begin{array}{l}\text { Lipotoxic effects on granulosa cells [60] } \\
\text { Leptin decreases AMH gene expression in cumulus and } \\
\text { granulosa cells [64] } \\
\text { Adiponectin modulates ovarian steroidogenesis [63] }\end{array}$ \\
\hline Smoking & $\begin{array}{l}\text { Smoking is inversely correlated with } \mathrm{AMH} \\
{[37,71,72]}\end{array}$ & $\begin{array}{l}\text { Polycyclic aromatic hydrocarbons cause oocyte } \\
\text { destruction in mice }[77,78] \\
\text { Nicotine and/or its metabolites accumulate in granulosa } \\
\text { cells and induce their apoptosis }[79,82] \\
\text { Cigarette smoke metabolites are associated with follicular } \\
\text { oxidative stress }[75]\end{array}$ \\
\hline Vitamin D deficiency & $\begin{array}{l}\text { Decreased serum vitamin D levels are associated } \\
\text { with lower serum AMH levels }[65,66]\end{array}$ & $\begin{array}{l}\text { Vitamin D-receptor complex binds the vitamin D } \\
\text { response element on the AMH gene promoter resulting } \\
\text { in upregulation of AMH gene expression [68] }\end{array}$ \\
\hline
\end{tabular}

JARID2: jumonji AT rich interactive domain 2; FMR1: fragile X mental retardation; BRCA1: breast cancer 1; AMH: antimüllerian hormone.

study by Merhi et al., the follicular fluid levels of leptin, another adipocytokine which is increased in obese women, were found to positively correlate with BMI and to suppress $\mathrm{AMH}$ and $\mathrm{AMH}$ receptor II gene expression in both cumulus and mural granulosa cells through the JAK2/STAT3 pathway [64]. Further studies are warranted to establish the mechanisms by which obesity decreases serum AMH levels and whether this reduction is reflective of reduced ovarian reserve or not.

Serum AMH concentration has been demonstrated to positively correlate with serum 25-hydroxyvitamin D $[25(\mathrm{OH}) \mathrm{D}]$ levels $[65,66]$, suggesting that vitamin $\mathrm{D}$ deficiency is associated with lower ovarian reserve. In addition, Coney et al. found that vitamin $\mathrm{D}$ levels are lower in African American compared with white women [67]. In their study, black women had lower median levels of serum $25(\mathrm{OH}) \mathrm{D}$ compared with white women $(27.3 \mathrm{nmol} / \mathrm{L}$ versus $52.4 \mathrm{nmol} / \mathrm{L} ; P<0.001)$, and $98 \%$ of black women had serum levels of $25(\mathrm{OH}) \mathrm{D}$ below $50 \mathrm{nmol} / \mathrm{L}$ compared with $45 \%$ of white women. Of note, the differences between the racial groups in the levels of $25(\mathrm{OH}) \mathrm{D}$ persisted despite adjustments for body weight, percentage body fat, and BMI [67]. These data suggest that vitamin D deficiency could account for racial differences in $\mathrm{AMH}$ between black and white women and that this effect is independent of BMI. Other than greater BMI, possible causes of lower vitamin $\mathrm{D}$ levels in black women include deeper skin pigmentation and decreased exposure to sunlight. Vitamin D may lead to increased AMH levels by a direct mechanism, as it was shown in a prostate cancer cell line that the $\mathrm{AMH}$ gene promoter has a vitamin $\mathrm{D}$ response element which binds the vitamin
D-receptor complex, resulting in upregulation of AMH gene expression [68]. Further molecular investigations should elucidate the mechanism by which vitamin D may affect $\mathrm{AMH}$ production in granulosa cells. Given the global epidemic of vitamin D insufficiency, especially in black women [69], the observations of a relationship between $\mathrm{AMH}$ and vitamin $\mathrm{D}$ suggest that vitamin D supplementation may improve fertility outcome and minimize racial differences in ovarian reserve. Future studies are warranted to investigate these possibilities.

Multiple epidemiologic studies have reported that cigarette smoking leads to reduced ovarian function and fertility and an earlier age at menopause, suggesting that smoking impairs ovarian reserve [70]. Indeed, Sowers et al. recently demonstrated that women who were smokers had an earlier age at menopause and a more rapid decline in $\mathrm{AMH}$ levels, suggesting that smoking may lead to either fewer oocytes or an earlier decline in oocyte number [71]. In agreement with this study, Plante et al. found that active smoking but not former or passive smoking was associated with decreased $\mathrm{AMH}$ values in late reproductive age and perimenopausal women [72]. The authors suggested that smoking may directly cause depletion of antral follicles but not primordial follicles, such that smoking cessation may permit repopulation of the growing follicular pool and normalization of AMH. Similar association between smoking and $\mathrm{AMH}$ was also recently reported by Schuh-Huerta et al. [37]. It is well-known that smoking status varies across racial groups. In a study of women's health across the nation (SWAN) which examined vasomotor symptoms longitudinally in a multiethnic sample of US women undergoing the perimenopausal transition, African Americans had the highest rate of active smoking (24.6\%), 
followed by Hispanics (16.7\%), whites (16.6\%), Japanese (12.9\%), and Chinese (1.6\%) [73]. Variations in smoking status among racial/ethnic groups may thus be potentially responsible for racial differences noted in ovarian reserve, as reflected by AMH.

The mechanism of tobacco's toxic effect on the ovary is unclear but may be due to effects on oocyte quantity [74], oocyte quality, or disruption of endocrine function [75, 76]. Animal studies suggest that polycyclic aromatic hydrocarbons (known carcinogens in cigarette smoke) cause oocyte destruction in mice [77, 78]. In addition, increased levels of nicotine metabolites and cigarette carcinogens have been noted in ovarian follicular fluid of active and passive smokers, indicating that toxic constituents of cigarette smoke including nicotine and cadmium have access to the follicular environment and could affect ovarian function [79-81]. Specifically, cotinine, a major metabolite of nicotine, was shown to accumulate in the nucleus and cytoplasm of granulosa cells [79], and nicotine has been shown to induce granulosa cell apoptosis [82], providing a possible explanation for reduced AMH levels observed in smokers.

In summary, accumulating evidence suggests that significant racial differences exist in ovarian reserve and reproductive aging. While multiple genetic and environmental factors may underlie these observed racial differences in $\mathrm{AMH}$, additional investigation is needed to determine their relative contribution to the time course of reproductive function and ovarian reserve. Further genome-wide association studies and well-designed longitudinal studies are expected to identify more underlying genetic factors and further increase our knowledge of the extent of reproductive aging differences across racial and ethnic groups. Improving our understanding of racial differences in ovarian reserve and their underlying causes may be essential for infertility treatment in minority women and lead to better reproductive planning, improved treatment outcomes, and timely interventions which may prolong reproductive lifespan in these women.

\section{References}

[1] T. Wu, P. Mendola, and G. M. Buck, "Ethnic differences in the presence of secondary sex characteristics and menarche among US girls: the third National Health and Nutrition Examination Survey, 1988-1994," Pediatrics, vol. 110, no. 4, pp. 752-757, 2002.

[2] M. E. Herman-Giddens, E. J. Slora, R. C. Wasserman et al., "Secondary sexual characteristics and menses in young girls seen in office practice: a study from the pediatric research in office settings network," Pediatrics, vol. 99, no. 4, pp. 505-512, 1997.

[3] J. C. Abma, A. Chandra, W. D. Mosher, L. S. Peterson, and L. J. Piccinino, "Fertility, family planning, and women's health: new data from the 1995 National Survey of Family Growth," Vital and Health Statistics, vol. 23, no. 19, pp. 1-114, 1997.

[4] E. H. Stephen and A. Chandra, "Declining estimates of infertility in the United States: 1982-2002," Fertility and Sterility, vol. 86, no. 3, pp. 516-523, 2006.

[5] F. I. Sharara and H. D. McClamrock, "Differences in in vitro fertilization (IVF) outcome between white and black women in an inner-city, university-based IVF program," Fertility and Sterility, vol. 73, no. 6, pp. 1170-1173, 2000.
[6] V. Y. Fujimoto, B. Luke, M. B. Brown et al., "Racial and ethnic disparities in assisted reproductive technology outcomes in the United States," Fertility and Sterility, vol. 93, no. 2, pp. 382-390, 2010.

[7] D. B. Seifer, R. Zackula, and D. A. Grainger, "Trends of racial disparities in assisted reproductive technology outcomes in black women compared with white women: society for Assisted Reproductive Technology 1999 and 2000 vs. 20042006," Fertility and Sterility, vol. 93, no. 2, pp. 626-635, 2010.

[8] D. B. Seifer, L. M. Frazier, and D. A. Grainger, "Disparity in assisted reproductive technologies outcomes in black women compared with white women," Fertility and Sterility, vol. 90, no. 5, pp. 1701-1710, 2008.

[9] V. L. Baker, B. Luke, M. B. Brown et al., "Multivariate analysis of factors affecting probability of pregnancy and live birth with in vitro fertilization: an analysis of the Society for Assisted Reproductive Technology Clinic Outcomes Reporting System," Fertility and Sterility, vol. 94, no. 4, pp. 1410-1416, 2010.

[10] T. Jain and M. D. Hornstein, "Disparities in access to infertility services in a state with mandated insurance coverage," Fertility and Sterility, vol. 84, no. 1, pp. 221-223, 2005.

[11] S. A. Missmer, D. B. Seifer, and T. Jain, "Cultural factors contributing to health care disparities among patients with infertility in Midwestern United States," Fertility and Sterility, vol. 95, no. 6, pp. 1943-1949, 2011.

[12] J. L. Stanford, P. Hartge, L. A. Brinton, R. N. Hoover, and R. Brookmeyer, "Factors influencing the age at natural menopause," Journal of Chronic Diseases, vol. 40, no. 11, pp. 995-1002, 1987.

[13] J. T. Bromberger, K. A. Matthews, L. H. Kuller, R. R. Wing, E. N. Meilahn, and P. Plantinga, "Prospective study of the determinants of age at menopause," American Journal of Epidemiology, vol. 145, no. 2, pp. 124-133, 1997.

[14] B. MacMahon and J. Worcester, "Age at menopause. United States 1960-1962," Vital and Health Statistics, vol. 11, no. 19, pp. $1-20,1966$.

[15] J. F. Randolph Jr., M. Sowers, E. B. Gold et al., "Reproductive hormones in the early menopausal transition: relationship to ethnicity, body size, and menopausal status," Journal of Clinical Endocrinology and Metabolism, vol. 88, no. 4, pp. 1516-1522, 2003.

[16] E. B. Gold, B. Sternfeld, J. L. Kelsey et al., "Relation of demographic and lifestyle factors to symptoms in a multi-racial/ethnic population of women 40-55 years of age," American Journal of Epidemiology, vol. 152, no. 5, pp. 463-473, 2000.

[17] E. W. Freeman, M. D. Sammel, C. R. Gracia et al., "Follicular phase hormone levels and menstrual bleeding status in the approach to menopause," Fertility and Sterility, vol. 83, no. 2, pp. 383-392, 2005.

[18] J. L. Luborsky, P. Meyer, M. F. Sowers, E. B. Gold, and N. Santoro, "Premature menopause in a multi-ethnic population study of the menopause transition," Human Reproduction, vol. 18, no. 1, pp. 199-206, 2003.

[19] D. B. Seifer and D. T. MacLaughlin, "Mullerian Inhibiting Substance is an ovarian growth factor of emerging clinical significance," Fertility and Sterility, vol. 88, no. 3, pp. 539-546, 2007.

[20] D. B. Seifer, D. T. MacLaughlin, B. P. Christian, B. Feng, and R. M. Shelden, "Early follicular serum müllerian-inhibiting substance levels are associated with ovarian response during assisted reproductive technology cycles," Fertility and Sterility, vol. 77, no. 3, pp. 468-471, 2002. 
[21] I. A. J. van Rooij, I. den Tonkelaar, F. J. M. Broekmans et al., "Anti-müllerian hormone is a promising predictor for the occurrence of the menopausal transition," Menopause, vol. 11, no. 6, pp. 601-606, 2004.

[22] A. de Vet, J. S. E. Laven, F. H. de Jong, A. P. N. Themmen, and B. C. J. M. Fauser, "Antimüllerian hormone serum levels: a putative marker for ovarian aging," Fertility and Sterility, vol. 77, no. 2, pp. 357-362, 2002.

[23] A. la Marca, G. Stabile, A. Carducci Artenisio, and A. Volpe, "Serum anti-Mullerian hormone throughout the human menstrual cycle," Human Reproduction, vol. 21, no. 12, pp. 3103-3107, 2006.

[24] A. la Marca, S. Giulini, R. Orvieto, V. de Leo, and A. Volpe, "Anti-Mullerian hormone concentrations in maternal serum during pregnancy," Human Reproduction, vol. 20, no. 6, pp. 1569-1572, 2005.

[25] A. Somunkiran, T. Yavuz, O. Yucel, and I. Ozdemir, "AntiMüllerian hormone levels during hormonal contraception in women with polycystic ovary syndrome," European Journal of Obstetrics Gynecology and Reproductive Biology, vol. 134, no. 2, pp. 196-201, 2007.

[26] D. B. Seifer, E. T. Golub, G. Lambert-Messerlian et al., "Variations in serum müllerian inhibiting substance between white, black, and Hispanic women," Fertility and Sterility, vol. 92, no. 5, pp. 1674-1678, 2009.

[27] N. Gleicher, A. Kim, A. Weghofer, and D. H. Barad, "Differences in ovarian aging patterns between races are associated with ovarian genotypes and sub-genotypes of the FMR1 gene," Reproductive Biology and Endocrinology, vol. 10, article 77, 2012.

[28] O. Rustamov, A. Smith, S. A. Roberts et al., "Anti-Mullerian hormone: poor assay reproducibility in a large cohort of subjects suggests sample instability," Human Reproduction, vol. 27, no. 10, pp. 3085-3091, 2012.

[29] O. Rustamov, P. W. Pemberton, S. A. Roberts et al., "The reproducibility of serum anti-Müllerian hormone in subfertile women: within and between patient variability," Fertility and Sterility, vol. 95, no. 3, pp. 1185-1187, 2011.

[30] E. Block, "Quantitative morphological investigations of the follicular system in women; variations at different ages," Acta Anatomica, vol. 14, no. 1-2, pp. 108-123, 1952.

[31] E. Block, "A quantitative morphological investigation of the follicular system in newborn female infants," Acta Anatomica, vol. 17, no. 3, pp. 201-206, 1953.

[32] E. A. McGee and A. J. W. Hsueh, "Initial and cyclic recruitment of ovarian follicles," Endocrine Reviews, vol. 21, no. 2, pp. 200$214,2000$.

[33] H. Snieder, A. J. Macgregor, and T. D. Spector, "Genes control the cessation of a woman's reproductive life: a twin study of hysterectomy and age at menopause," Journal of Clinical Endocrinology and Metabolism, vol. 83, no. 6, pp. 1875-1880, 1998.

[34] J. P. de Bruin, H. Bovenhuis, P. A. H. Van Noord et al., "The role of genetic factors in age at natural menopause," Human Reproduction, vol. 16, no. 9, pp. 2014-2018, 2001.

[35] J. M. Meyer, L. J. Eaves, A. C. Heath, and N. G. Martin, "Estimating genetic influences on the age-at-menarche: a survival analysis approach," American Journal of Medical Genetics, vol. 39, no. 2, pp. 148-154, 1991.

[36] M. P. Rosen, E. B. Johnstone, S. J. Gillham et al., "Is antral follicle count a genetic trait?" Menopause, vol. 17, no. 1, pp. 109-113, 2010 .
[37] S. M. Schuh-Huerta, N. A. Johnson, M. P. Rosen, B. Sternfeld, M. I. Cedars, and R. A. Reijo Pera, "Genetic variants and environmental factors associated with hormonal markers of ovarian reserve in Caucasian and African American women," Human Reproduction, vol. 27, no. 2, pp. 594-608, 2012.

[38] I. Ben-Shlomo, U. A. Vitt, and A. J. W. Hsueh, "Perspective: the ovarian kaleidoscope database-II. Functional genomic analysis of an organ-specific database," Endocrinology, vol. 143, no. 6, pp. 2041-2044, 2002.

[39] S. M. Schuh-Huerta, N. A. Johnson, M. P. Rosen, B. Sternfeld, M. I. Cedars, and R. A. Reijo Pera, "Genetic markers of ovarian follicle number and menopause in women of multiple ethnicities," Human Genetics, vol. 131, no. 11, pp. 1709-1724, 2012.

[40] N. Gleicher, A. Weghofer, K. Oktay, and D. Barad, "Relevance of triple CGG repeats in the FMR1 gene to ovarian reserve," Reproductive Biomedicine Online, vol. 19, no. 3, pp. 385-390, 2009.

[41] N. Gleicher, A. Weghofer, and D. H. Barad, "Ovarian reserve determinations suggest new function of FMR1 (fragile X gene) in regulating ovarian ageing," Reproductive BioMedicine Online, vol. 20, no. 6, pp. 768-775, 2010.

[42] N. Gleicher, A. Weghofer, A. Kim, and D. H. Barad, "The impact in older women of ovarian FMR1 genotypes and sub-genotypes on ovarian reserve," PLoS ONE, vol. 7, no. 3, Article ID e33638, 2012.

[43] N. Gleicher, A. Weghofer, and D. H. Barad, "Effects of race/ethnicity on triple CGG counts in the FMR1 gene in infertile women and egg donors," Reproductive BioMedicine Online, vol. 20, no. 4, pp. 485-491, 2010.

[44] S. A. Narod, "BRCA mutations in the management of breast cancer: the state of the art," Nature Reviews Clinical Oncology, vol. 7, no. 12, pp. 702-707, 2010.

[45] N. D. Kauff, J. M. Satagopan, M. E. Robson et al., "Risk-reducing salpingo-oophorectomy in women with a BRCA1 or BRCA2 mutation," The New England Journal of Medicine, vol. 346, no. 21, pp. 1609-1615, 2002.

[46] K. Oktay, J. Y. Kim, D. Barad, and S. N. Babayev, "Association of BRCA1 mutations with occult primary ovarian insufficiency: a possible explanation for the link between infertility and breast/ovarian cancer risks," Journal of Clinical Oncology, vol. 28, no. 2, pp. 240-244, 2010.

[47] I. Rzepka-Górska, B. Tarnowski, A. Chudecka-Głaz, B. Górski, D. Zielińska, and A. Tołoczko-Grabarek, "Premature menopause in patients with BRCA1 gene mutation," Breast Cancer Research and Treatment, vol. 100, no. 1, pp. 59-63, 2006.

[48] S. Titus, F. Li, R. Stobezki et al., "Impairment of BRCA1-related DNA double-strand break repair leads to ovarian aging in mice and humans," Science Translational Medicine, vol. 5, Article ID 172ra121, 2013.

[49] E. M. John, A. Miron, G. Gong et al., "Prevalence of pathogenic BRCA1 mutation carriers in 5 US racial/ethnic groups," Journal of the American Medical Association, vol. 298, no. 24, pp. 28692876, 2007.

[50] B. Newman, H. Mu, L. M. Butler, R. C. Millikan, P. G. Moorman, and M.-C. King, "Frequency of breast cancer attributable to BRCA1 in a population-based series of American women," Journal of the American Medical Association, vol. 279, no. 12, pp. 915-921, 1998.

[51] K. E. Malone, J. R. Daling, D. R. Doody et al., "Prevalence and predictors of BRCA1 and BRCA2 mutations in a populationbased study of breast cancer in white and black American 
women ages 35 to 64 years," Cancer Research, vol. 66, no. 16, pp. 8297-8308, 2006.

[52] K. M. Flegal, M. D. Carroll, C. L. Ogden, and L. R. Curtin, "Prevalence and trends in obesity among US adults, 1999-2008," Journal of the American Medical Association, vol. 303, no. 3, pp. 235-241, 2010.

[53] M. S. Kupka, C. Gnoth, K. Buehler, W. Dahncke, and J.-S. Kruessel, "Impact of female and male obesity on IVF/ICSI: Results of 700,000 ART-cycles in Germany," Gynecological Endocrinology, vol. 27, no. 3, pp. 144-149, 2011.

[54] D. Zhang, Y. Zhu, H. Gao et al., "Overweight and obesity negatively affect the outcomes of ovarian stimulation and invitro fertilisation: a cohort study of 2628 Chinese women," Gynecological Endocrinology, vol. 26, no. 5, pp. 325-332, 2010.

[55] A. Maheshwari, L. Stofberg, and S. Bhattacharya, "Effect of overweight and obesity on assisted reproductive technology-a systematic review," Human Reproduction Update, vol. 13, no. 5, pp. 433-444, 2007.

[56] H. Dechaud, T. Anahory, L. Reyftmann, V. Loup, S. Hamamah, and B. Hedon, "Obesity does not adversely affect results in patients who are undergoing in vitro fertilization and embryo transfer," European Journal of Obstetrics Gynecology and Reproductive Biology, vol. 127, no. 1, pp. 88-93, 2006.

[57] E. W. Freeman, C. R. Gracia, M. D. Sammel, H. Lin, L. C.-L. Lim, and J. F. Strauss III, "Association of anti-mullerian hormone levels with obesity in late reproductive-age women," Fertility and Sterility, vol. 87, no. 1, pp. 101-106, 2007.

[58] A. Z. Steiner, F. Z. Stanczyk, S. Patel, and A. Edelman, "Antimullerian hormone and obesity: insights in oral contraceptive users," Contraception, vol. 81, no. 3, pp. 245-248, 2010.

[59] E. Buyuk, D. B. Seifer, E. Illions, R. V. Grazi, and H. Lieman, "Elevated body mass index is associated with lower serum antimullerian hormone levels in infertile women with diminished ovarian reserve but not with normal ovarian reserve," Fertility and Sterility, vol. 95, no. 7, pp. 2364-2368, 2011.

[60] L. L.-Y. Wu, K. R. Dunning, X. Yang et al., "High-fat diet causes lipotoxicity responses in cumulus-oocyte complexes and decreased fertilization rates," Endocrinology, vol. 151, no. 11, pp. 5438-5445, 2010.

[61] H. I. Su, M. D. Sammel, E. W. Freeman, H. Lin, T. Deblasis, and C. R. Gracia, "Body size affects measures of ovarian reserve in late reproductive age women," Menopause, vol. 15, no. 5, pp. 857861,2008

[62] T. Kadowaki and T. Yamauchi, "Adiponectin and adiponectin receptors," Endocrine Reviews, vol. 26, no. 3, pp. 439-451, 2005.

[63] S. Ledoux, D. B. Campos, F. L. Lopes, M. Dobias-Goff, M.-F. Palin, and B. D. Murphy, "Adiponectin induces periovulatory changes in ovarian follicular cells," Endocrinology, vol. 147, no. 11, pp. 5178-5186, 2006.

[64] Z. Merhi, E. Buyuk, D. S. Berger et al., "Leptin suppresses antiMullerian hormone gene expression through the JAK2/STAT3 pathway in luteinized granulosa cells of women undergoing IVF," Human Reproduction, vol. 28, no. 6, pp. 1661-1669, 2013.

[65] Z. O. Merhi, D. B. Seifer, J. Weedon et al., "Circulating vitamin $\mathrm{D}$ correlates with serum antimüllerian hormone levels in latereproductive-aged women: Women's Interagency HIV Study," Fertility and Sterility, vol. 98, pp. 228-234, 2012.

[66] N. A. Dennis, L. A. Houghton, G. T. Jones, A. M. van Rij, K. Morgan, and I. S. McLennan, "The level of serum antimullerian hormone correlates with vitamin d status in men and women but not in boys," The Journal of Clinical Endocrinology \& Metabolism, vol. 97, pp. 2450-2455, 2012.
[67] P. Coney, L. M. Demers, W. C. Dodson, A. R. Kunselman, G. Ladson, and R. S. Legro, "Determination of vitamin D in relation to body mass index and race in a defined population of black and white women," International Journal of Gynecology \& Obstetrics, vol. 119, no. 1, pp. 21-25, 2012.

[68] P. J. Malloy, L. Peng, J. Wang, and D. Feldman, "Interaction of the vitamin D receptor with a vitamin D response element in the müllerian-inhibiting substance (MIS) promoter: Regulation of MIS expression by calcitriol in prostate cancer cells," Endocrinology, vol. 150, no. 4, pp. 1580-1587, 2009.

[69] O. M. Adeyemi, D. Agniel, A. L. French et al., "Vitamin D deficiency in HIV-infected and HIV-uninfected women in the United States," Journal of Acquired Immune Deficiency Syndromes, vol. 57, no. 3, pp. 197-204, 2011.

[70] M. R. Sowers and M. T. La Pietra, "Menopause: its epidemiology and potential association with chronic diseases," Epidemiologic Reviews, vol. 17, no. 2, pp. 287-302, 1995.

[71] M. R. Sowers, D. McConnell, M. Yosef, M. L. Jannausch, S. D. Harlow, and J. F. Randolph Jr., "Relating smoking, obesity, insulin resistance, and ovarian biomarker changes to the final menstrual period," Annals of the New York Academy of Sciences, vol. 1204, pp. 95-103, 2010.

[72] B. J. Plante, G. S. Cooper, D. D. Baird, and A. Z. Steiner, “The impact of smoking on antimüllerian hormone levels in women aged 38 to 50 years," Menopause, vol. 17, no. 3, pp. 571-576, 2010.

[73] E. B. Gold, A. Colvin, N. Avis et al., "Longitudinal analysis of the association between vasomotor symptoms and race/ethnicity across the menopausal transition: study of women's health across the nation," American Journal of Public Health, vol. 96, no. 7, pp. 1226-1235, 2006.

[74] D. R. Mattison and S. S. Thorgeirsson, "Smoking and industrial pollution, and their effects on menopause and ovarian cancer," The Lancet, vol. 1, no. 8057, pp. 187-188, 1978.

[75] T. Paszkowski, R. N. Clarke, and M. D. Hornstein, "Smoking induces oxidative stress inside the Graafian follicle," Human Reproduction, vol. 17, no. 4, pp. 921-925, 2002.

[76] K. E. Valdez and B. K. Petroff, "Potential roles of the aryl hydrocarbon receptor in female reproductive senescence," Reproductive Biology, vol. 4, no. 3, pp. 243-258, 2004.

[77] B. J. Gulyas and D. R. Mattison, "Degeneration of mouse oocytes in response to polycyclic aromatic hydrocarbons," Anatomical Record, vol. 193, no. 4, pp. 863-882, 1979.

[78] D. R. Mattison and S. S. Thorgeirsson, "Ovarian aryl hydrocarbon hydroxylase activity and primordial oocyte toxicity of polycyclic aromatic hydrocarbons in mice," Cancer Research, vol. 39, no. 9, pp. 3471-3475, 1979.

[79] M. T. Zenzes, L. A. Puy, and R. Bielecki, "Immunodetection of cotinine protein in granulosa-lutein cells of women exposed to cigarette smoke," Fertility and Sterility, vol. 68, no. 1, pp. 76-82, 1997.

[80] M. T. Zenzes, S. Krishnan, B. Krishnan, H. Zhang, and R. F. Casper, "Cadmium accumulation in follicular fluid of women in in vitro fertilization-embryo transfer is higher in smokers," Fertility and Sterility, vol. 64, no. 3, pp. 599-603, 1995.

[81] T. Weiss and A. Eckert, "Cotinine levels in follicular fluid and serum of IVF patients: effect on granulose-luteal cell function in vitro," Human Reproduction, vol. 4, no. 5, pp. 482-485, 1989.

[82] R. Bordel, M. W. Laschke, M. D. Menger, and B. Vollmar, "Nicotine does not affect vascularization but inhibits growth of freely transplanted ovarian follicles by inducing granulosa cell apoptosis," Human Reproduction, vol. 21, no. 3, pp. 610-617, 2006. 


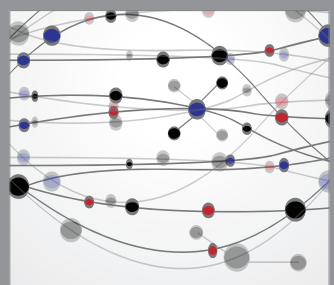

The Scientific World Journal
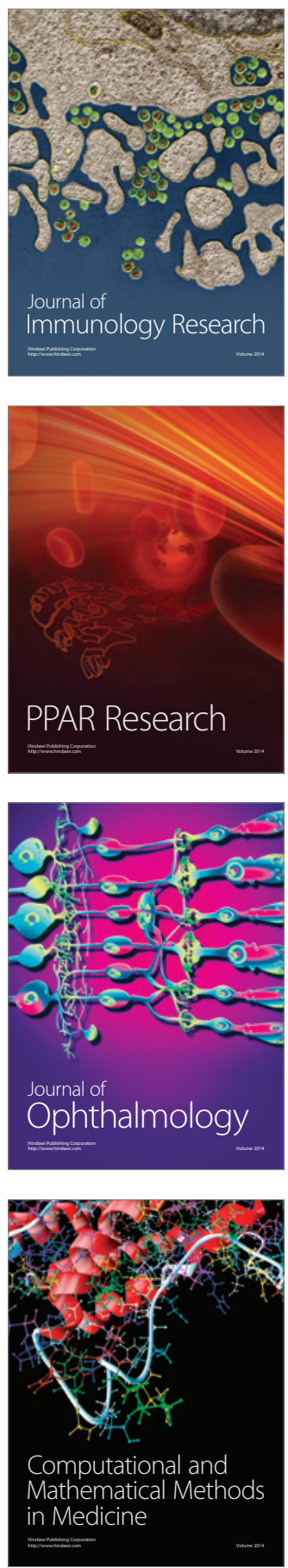

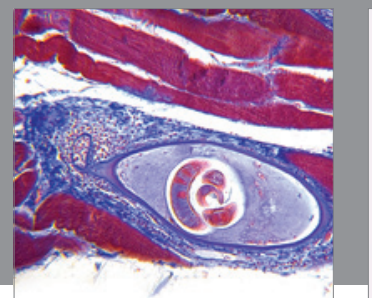

Gastroenterology

Research and Practice
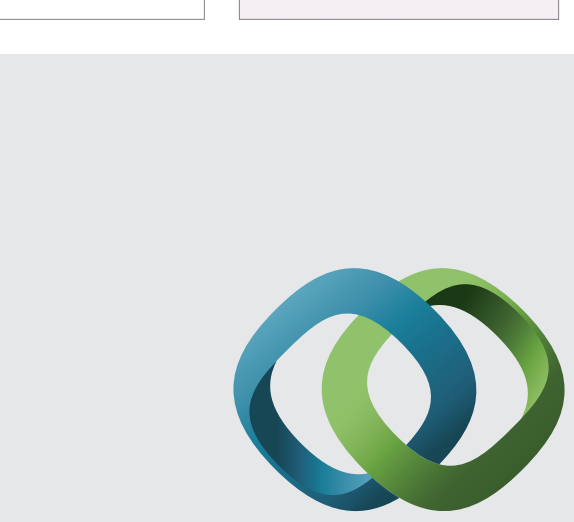

\section{Hindawi}

Submit your manuscripts at

http://www.hindawi.com
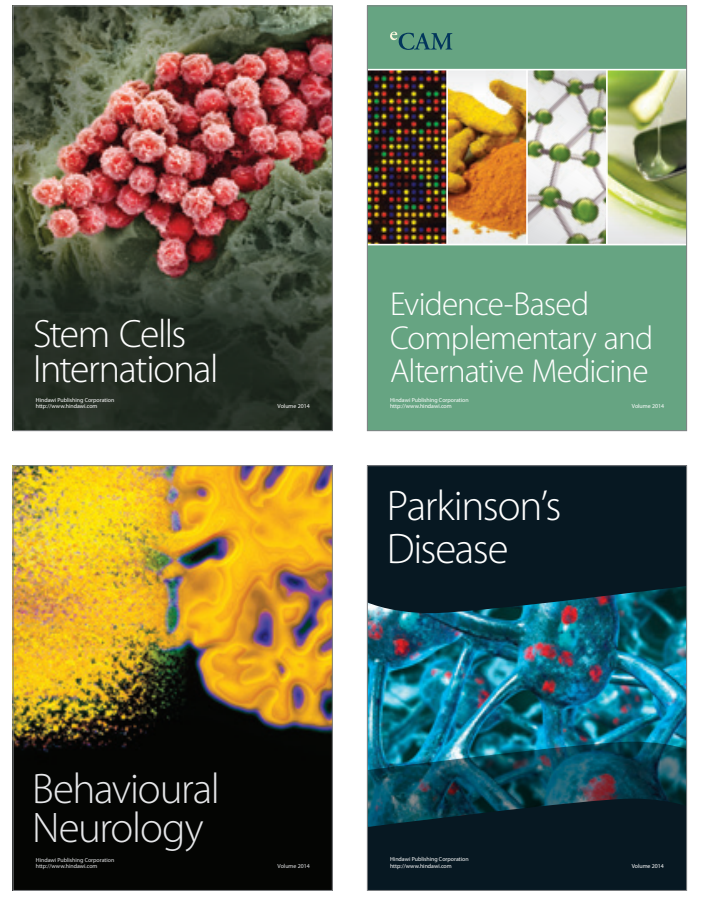
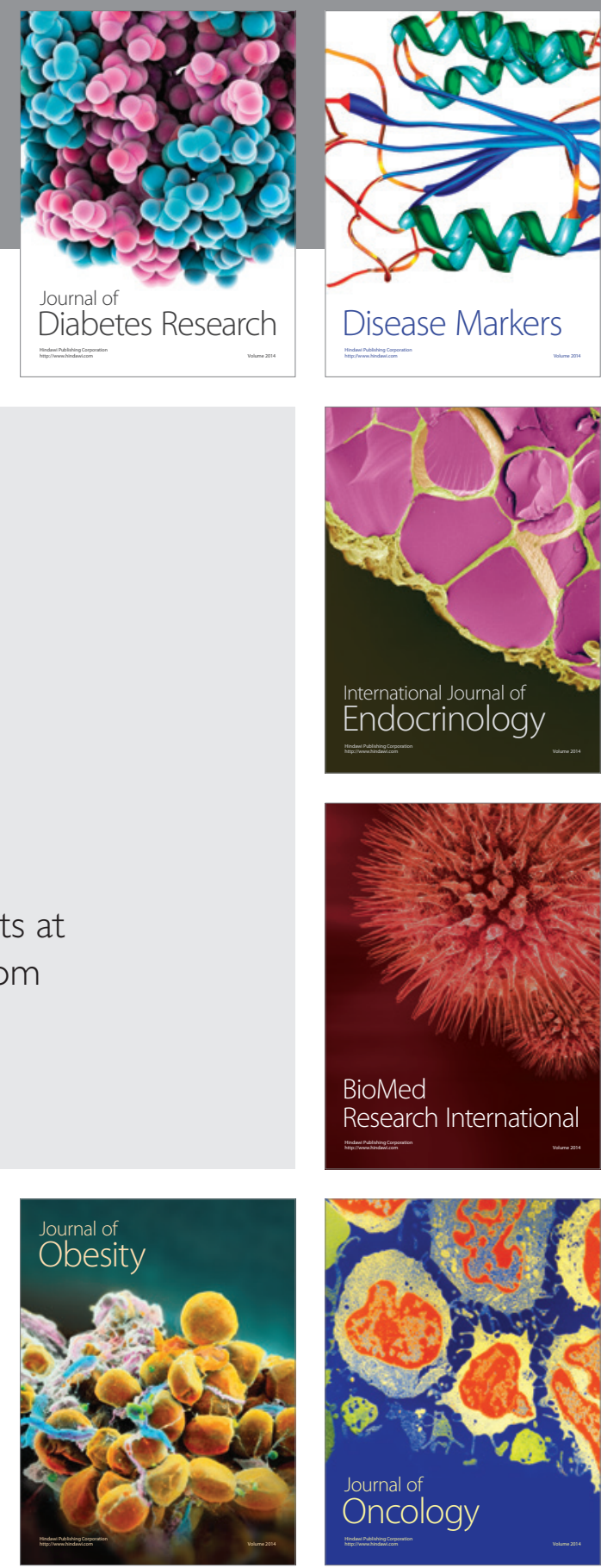

Disease Markers
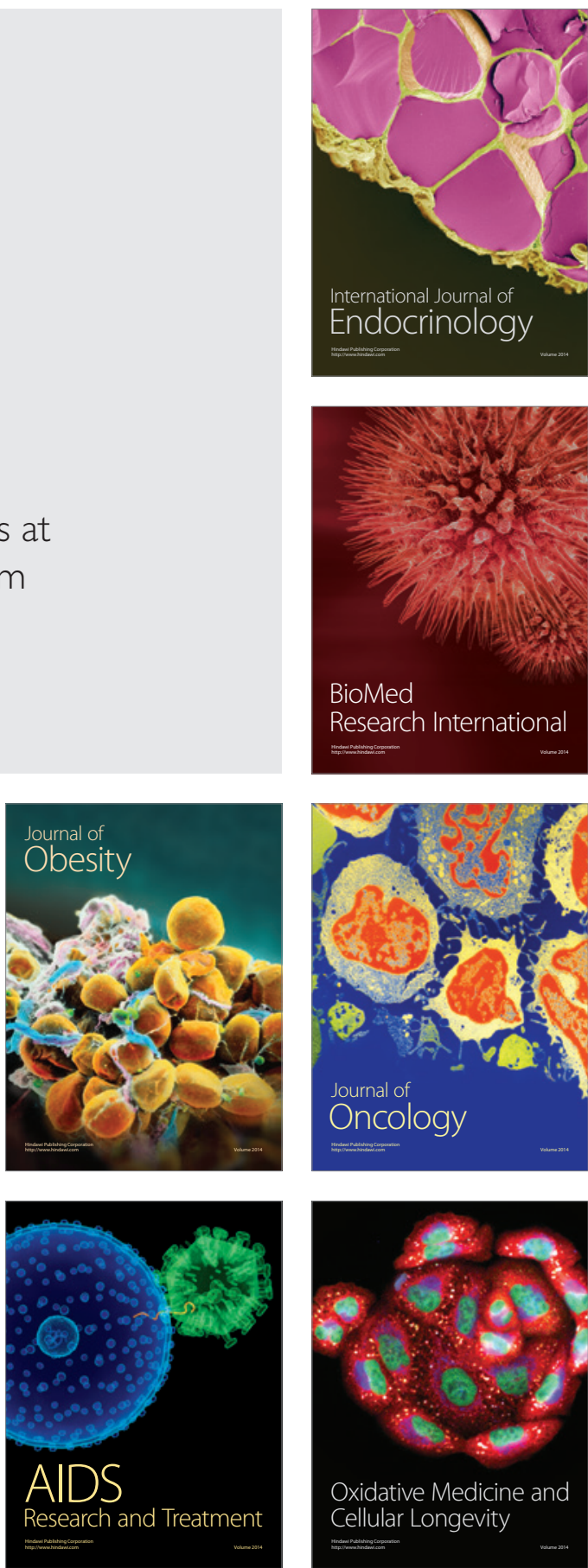